\title{
G

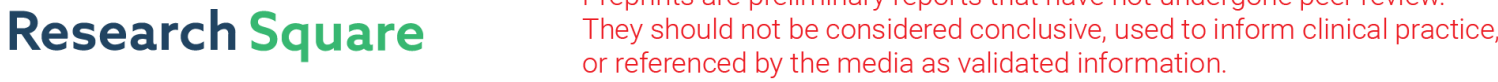 \\ Exploring Trimetallic Clusters Containing Alkali and Alkaline Earth Metal Atoms with High Activity for Nitrogen Activation
}

\section{Xue-Qian Huang}

North China Electric Power University

Xun-Lei Ding ( $\nabla$ dingxl@ncepu.edu.cn )

North China Electric Power University https://orcid.org/0000-0002-9962-714X

Jian Wang

North China Electric Power University

Ya-Ya Wang

North China Electric Power University

Joseph Israel Gurti

North China Electric Power University

\section{Yan Chen}

North China Electric Power University

Meng-Meng Wang

North China Electric Power University

Wei Li

North China Electric Power University

Xin Wang

North China Electric Power University

\section{Research Article}

Keywords: Density functional theory, Nitrogen reduction reaction, Trimetallic clusters, Alkali metal, Alkaline earth metal

Posted Date: January 24th, 2022

DOI: https://doi.org/10.21203/rs.3.rs-1262399/v1

License: (c) (1) This work is licensed under a Creative Commons Attribution 4.0 International License.

Read Full License 
Version of Record: A version of this preprint was published at Structural Chemistry on April 4th, 2022. See the published version at https://doi.org/10.1007/s11224-022-01919-x. 


\section{Abstract}

Activation of dinitrogen (N2) is the critical step in nitrogen reduction reaction (NRR) in ammonia synthesis. In this paper, reaction mechanisms of N2 activation on trimetallic clusters Mo2M (M=Li, Na, K, $\mathrm{Mg}$, and $\mathrm{Ca})$ and Mo3-xCax $(\mathrm{x}=2-3)$ were systematically studied by density functional theory calculations. Unlike Mo2 which is inert to N2 , clusters with alkali or alkaline earth metal atoms have much higher reactivity towards N2 in terms of both thermodynamics and kinetics. Particularly, in one reaction path of $\mathrm{N} 2$ with $\mathrm{MoCa} 2$, all the intermediates and transition states are well below the energy sum of the reactants, indicating that the dissociation of $\mathrm{N} 2$ on MoCa2 can take place spontaneously in gas-phase reactions. N2 transfers on clusters with different coordination modes, and the $\mathrm{N}-\mathrm{N}$ bond is gradually activated. When $\mathrm{N} 2$ is bonded with three metal atoms with end-on:side-on:side-on coordination mode, it is fully activated and easily dissociated into two adsorbed $\mathrm{N}$ atoms. These results may serve as a prototype to design single-cluster catalysts with a trimetallic center for nitrogen activation and conversion.

\section{Introduction}

Nitrogen-containing compounds are useful not only in agriculture [1] but also in new energy sources [2-6]. However, $\mathrm{N}_{2}$ is difficult to be activated because of its strong $\mathrm{N} \equiv \mathrm{N}$ triple bonds, large highest occupied molecular orbital-lowest unoccupied molecular orbital gap, and large ionization energy [7, 8]. At present, the most common large-scale nitrogen fixation process in the industry is Haber-Bosch, which requires a high temperature up to $400{ }^{\circ} \mathrm{C}$ and high pressure up to $15-25 \mathrm{MPa}$ to produce ammonia through nitrogen reduction reaction (NRR) [9-14]. In the process of NRR, the environmental pollution caused by such a high temperature and pressure is very serious, so nitrogen fixation is a challenging and vital problem both in chemistry and industry. It is urgent to design new catalysts to convert $\mathrm{N}_{2}$ into nitrogen-containing compounds much more effectively under mild conditions $[15,16]$.

The development of single-atom catalysis (SAC) provides a new idea for catalyst design [17]. SAC can improve the atomic utilization of precious metals to the limit, and the active center is quite uniform, which improves the selectivity of catalytic reactions and reduces the occurrence of side reactions [18-20]. However, the coordination modes of $\mathrm{N}_{2}$ on the single metal atom is limited, only end-on or side-on, which is not conducive to the activation of $\mathrm{N}-\mathrm{N}$ bond. It has been predicted that diatomic catalysts may have better NRR activity [21, 22]. Then in 2018, Li et al. found that $\mathrm{Fe}_{3}$ clusters fixed on the surface of $\theta-\mathrm{Al}_{2} \mathrm{O}_{3}$ can be good catalysts for heterogeneous ammonia synthesis [23]. The catalytic mechanism of $\mathrm{N}_{2}$ conversion to $\mathrm{NH}_{3}$ on $\mathrm{Fe}_{3} / \mathrm{Al}_{2} \mathrm{O}_{3}(010)$ was studied theoretically. They further studied the catalytic mechanism of $\mathrm{N}_{2}$ to $\mathrm{NH}_{3}$ on monodisperse $\mathrm{Rh}_{1} \mathrm{Co}_{3} / \mathrm{CoO}$ (011) [24]. A new concept of single-cluster catalysis (SCC) was proposed, which provides a new strategy for designing new catalysts especially for complicated reactions such as NRR. However, the catalytic mechanisms of the reaction on surfaces are very complicated, and the effect of the number of metal atoms on the reaction activity is not clear. 
Gas-phase clusters are ideal models for simulating the active sites of related condensed phase systems, which can be used to understand the bond activation process under isolated and well-controlled conditions at a strictly molecular level [25-28], and is suitable to provide insights into the mechanisms of SAC and SCC [29]. A large number of experiments and theoretical work have explored the mechanism of $\mathrm{N}_{2}$ activation by gas-phase clusters, mainly focusing on metal clusters [30-35], metal carbide clusters [36, $37]$, and metal nitride clusters $[38,39]$. Coordination modes of $\mathrm{N}_{2}$ on supporting atoms were found critical for $\mathrm{N}_{2}$ activation. On bimetallic clusters, $\mathrm{N}_{2}$ can first obtain the adsorption intermediate of side-on:end-on and then dissociate [35,37], or it can pass through the intermediate of side-on:side-on and then dissociate [40-42]. On trimetallic clusters, $\mathrm{N}_{2}$ is adsorbed on the center of the metal triangle in the form of end-on:side-on:side-on or end-on:end-on:side-on coordination modes before dissociation [43-46].

In the theoretical work of some bulk phases, it is predicted that trimetallic clusters can have good NRR activity $[23,47]$. Some studies have shown that there are various coordination modes of $\mathrm{N}_{2}$ on three metal atoms, which is beneficial for the dissociation of $\mathrm{N} \equiv \mathrm{N}$ triple bonds [23]. Experimental and theoretical studies on gas-phase clusters also showed that the clusters containing three active metal atoms can cleave the $\mathrm{N} \equiv \mathrm{N}$ triple bond under mild conditions [43-45, 48]. In addition, three atoms can reflect more comprehensively the complexity of the geometric and electronic structures of the active centers. The study of the reaction process of trimetallic clusters with nitrogen molecules is helpful to understand the activation mechanisms of nitrogen molecules deeply. Therefore, we will focus on $\mathrm{N}_{2}$ activation on trimetallic clusters in this work.

Previous experimental studies have found that the doping of alkali/alkaline earth metals into the catalysts (e.g., Ru) can promote NRR sufficiently [49]. The reason is that the doped metals are easy to provide electrons so that the $\pi^{*}$ antibond orbitals of $N_{2}$ can obtain electrons to activate the $N \equiv N$ triple bonds. However, there are few studies on the interaction between alkali /alkaline earth metal atoms with $\mathrm{N}_{2}$ [50], let alone the study of trimetallic clusters. Therefore, in this work, based on $\mathrm{Mo}_{2}$ clusters, we try to introduce alkali and alkaline earth metal atoms into systems to investigate the microscopic mechanism of the $\mathrm{N} \equiv \mathrm{N}$ bond activation on these clusters and explore systems with high reactivity. The specific research systems include $\mathrm{Mo}_{2}, \mathrm{Mo}_{2} \mathrm{M}(\mathrm{M}=\mathrm{Li}, \mathrm{Na}, \mathrm{K}, \mathrm{Mg}$, and $\mathrm{Ca})$, and $\mathrm{Mo}_{3-x} \mathrm{Ca}_{x}(x=2-3)$.

\section{Calculation Methods}

Density functional theory (DFT) calculations using the Gaussian 09 program package [51] were carried out to investigate the structures of $\mathrm{Mo}_{2}, \mathrm{Mo}_{2} \mathrm{M}(\mathrm{M}=\mathrm{Li}, \mathrm{Na}, \mathrm{K}, \mathrm{Mg}$, and $\mathrm{Ca})$, and $\mathrm{Mo}_{3-x} \mathrm{Ca}_{x}(x=2-3)$ as well as the reaction mechanisms of $\mathrm{Mo}_{2}+\mathrm{N}_{2}, \mathrm{Mo}_{2} \mathrm{M}+\mathrm{N}_{2}$, and $\mathrm{Mo}_{3-x} \mathrm{Ca}_{x}(x=2-3)+\mathrm{N}_{2}$. The $\mathrm{Mo}_{2}+\mathrm{N}_{2}, \mathrm{Mo}_{2} \mathrm{M}+$ $\mathrm{N}_{2}$, and $\mathrm{Mo}_{3-x} \mathrm{Ca}_{x}(x=2-3)+\mathrm{N}_{2}$ are optimized using the TPSS functional [52] and def2-TZVP basis set

$[50,53]$. The adsorption energy of $\mathrm{N}_{2}$ on the $\mathrm{Mo}_{2} \mathrm{M}$ cluster is defined as $E_{a d}=E_{\left(\mathrm{Mo}_{2} \mathrm{M}_{-} \mathrm{N}_{2}\right)}-E_{\left(\mathrm{Mo}_{2} \mathrm{M}\right)}-E_{\left(\mathrm{N}_{2}\right)}$, where $E$ is the total electron energy corrected with zero-point vibration energy (ZPE). It is clear that $E_{\mathrm{ad}}$ is also the relative energy with respect to the separated reactants. Harmonic vibration frequencies of the 
optimized structures are calculated at the same theoretical level to determine the properties of stagnation points (the minimum has no imaginary frequency, and the transition state has only one imaginary frequency). The $\mathrm{N}-\mathrm{N}$ bond length $\left(R_{\mathrm{N}-\mathrm{N}}\right)$, Mayer bond order $\left(\mathrm{MBO}_{\mathrm{N}-\mathrm{N}}\right)$, bond vibration frequency $\left(v_{\mathrm{N}-\mathrm{N}}\right)$, and Hirshfeld charge transfer $\left(Q_{\mathrm{N} 2}\right)$ of key intermediates and transition states were calculated by the Multiwfn program [54], to measure the activation degree of $\mathrm{N}_{2}$ during the reaction of $\mathrm{N}_{2}$ with $\mathrm{Mo}_{2} \mathrm{M}$ and $\mathrm{Mo}_{3-x} \mathrm{Ca}_{x}(x=2-3)$.

\section{Results And Discussion}

\subsection{Activation of $\mathrm{N}_{2}$ on $\mathrm{Mo}_{2}$ cluster}

Reaction mechanisms of $\mathrm{N}_{2}$ activation on $\mathrm{Mo}_{2}$ were studied at first to compare with subsequent investigations on $\mathrm{Mo}_{2}$ doped with alkali or alkaline earth metal atoms. Fig. 1 shows the reaction path between singlet $\mathrm{Mo}_{2}$ and $\mathrm{N}_{2} . \mathrm{N}_{2}$ is adsorbed on a Mo atom in the end-on coordination mode to form an intermediate (11) with small adsorption energy $\left(E_{\mathrm{ad}}\right)$ of $-0.27 \mathrm{eV}$ and a weak activation of $\mathrm{N}-\mathrm{N}$ bond length of $112 \mathrm{pm}\left(\mathrm{N}-\mathrm{N}\right.$ bond length of free $\mathrm{N}_{2}$ molecule is $110 \mathrm{pm}$ ). The system forms a stable $\mathrm{I} 2$ by overcoming a low energy barrier (TS1, $0.38 \mathrm{eV}$ ). In I2, $\mathrm{N}_{2}$ is adsorbed on a Mo atom in side-on, and the $\mathrm{N}-\mathrm{N}$ bond length is $113 \mathrm{pm}$. Then, by overcoming a higher energy barrier (TS2, $0.72 \mathrm{eV})$, the coordination mode of $\mathrm{N}_{2}$ changes from side-on to end-on:side-on (I3). The energy above zero point (IS1) $0.82 \mathrm{eV}, \mathrm{N}-\mathrm{N}$ bond is prolonged from 113 to $124 \mathrm{pm}$. The $\mathrm{N}-\mathrm{N}$ bond in $\mathrm{I} 3$ can be directly dissociated by transition state 3 (TS3) to obtain the final product $15(-0.48 \mathrm{eV})$, but it needs to overcome a very high energy barrier (TS3, $0.92 \mathrm{eV}$ ). Alternatively, it can also be converted to side-on:side-on structure is adsorbed on two Mo atoms (14), and then $\mathrm{N}-\mathrm{N}$ dissociates through TS4, but this step requires a higher energy barrier (1.48 eV).

It can be seen that $\mathrm{N}_{2}$ has different adsorption configurations on $\mathrm{Mo}_{2}$ diatoms, among which the energy of $\mathrm{N}_{2}$ adsorption on end-on is the lowest, and the conversion of different adsorption configurations needs to overcome energy barriers. Although $\mathrm{N}_{2}$ dissociation is an exothermic reaction (the head release is about $0.5 \mathrm{eV}$ ) on $\mathrm{Mo}_{2}$ diatom, the dissociation of the $\mathrm{N}-\mathrm{N}$ bond needs to overcome high energy barriers, so it is difficult for $\mathrm{Mo}_{2}$ to react directly with $\mathrm{N}_{2}$ to dissociate the $\mathrm{N}-\mathrm{N}$ bond. Nitrogen adsorption sites and adsorption modes of diatomic metal clusters are relatively simple. Adding another metal atom to the diatomic can increase the diversity of nitrogen adsorption sites and adsorption modes. Next, we introduce alkali and alkaline earth metal atoms into $\mathrm{Mo}_{2}$ clusters to explorer more reactive clusters towards $\mathrm{N}_{2}$ activation.

\subsection{Reaction of $\mathrm{Mo}_{2} \mathrm{M}(\mathrm{M}=\mathrm{Li}, \mathrm{Na}, \mathrm{K}, \mathrm{Mg}$, and $\mathrm{Ca})$ with $\mathrm{N}_{2}$}

\subsubsection{Adsorption of $\mathrm{N}_{2}$ molecules at different sites of $\mathrm{Mo}_{2} \mathrm{M}$}


Optimized structures of $\mathrm{Mo}_{2} \mathrm{M}(\mathrm{M}=\mathrm{Li}, \mathrm{Na}, \mathrm{K}, \mathrm{Mg}$, and $\mathrm{Ca})$ clusters are all triangles, as shown in Fig. 2 . $\mathrm{Mo}_{2} \mathrm{Li} / \mathrm{Na} / \mathrm{K}$ are doublet electronic state and $\mathrm{Mo}_{2} \mathrm{Mg} / \mathrm{Ca}$ are triplet state. Then, two possible initial adsorption sites of nitrogen molecules onto these clusters have been tested. One of the initial adsorption configurations is that $\mathrm{N}_{2}$ is close to a Mo atom (Fig. 2a). After optimization, $\mathrm{N}_{2}$ is adsorbed on a Mo atom in end-on coordination mode, and the $\mathrm{N}-\mathrm{N}$ bond is extended from 110 to $113-114 \mathrm{pm}$. The adsorption energies $\left(E_{\mathrm{ad}}\right)$ of $\mathrm{N}_{2}$ on this site for different clusters are similar, with the absolute values $\left(\left|E_{\mathrm{ad}}\right|\right)$ about 0.6-0.7 eV. The other initial adsorption configuration is that $\mathrm{N}_{2}$ is close to the doped $\mathrm{M}$, and two different adsorption modes are found after optimization (Fig. 2b). In the systems doped with alkali metal atoms Li, $\mathrm{Na}$, or $\mathrm{K}, \mathrm{N}_{2}$ is adsorbed on the alkali metal atom with the end-on coordination mode, with relatively small $\left|E_{\mathrm{ad}}\right|$, (less than $0.4 \mathrm{eV}$ ). The $\mathrm{N} \equiv \mathrm{N}$ bond length is unchanged compared with that of the free $\mathrm{N}_{2}$. In the systems doped with alkaline earth metal atoms $\mathrm{Mg}$ or $\mathrm{Ca}, \mathrm{N}_{2}$ is adsorbed on $\mathrm{M}$ and Mo two metal atoms with the coordination mode of side-on:end-on. $\left|E_{\mathrm{ad}}\right|$ of $\mathrm{Mo}_{2} \mathrm{Mg}$ is still small $(0.43 \mathrm{eV})$ while that of $\mathrm{Mo}_{2} \mathrm{Ca}$ is as large as $0.90 \mathrm{eV}$. The $\mathrm{N}-\mathrm{N}$ bond is extended from 110 to $119 \mathrm{pm}$, showing a certain degree of activation.

Compared with the case of $\mathrm{Mo}_{2}$, when $\mathrm{N}_{2}$ is adsorbed on $\mathrm{Mo}$ atoms of $\mathrm{Mo}_{2} \mathrm{M}(\mathrm{M}=\mathrm{Li}, \mathrm{Na}, \mathrm{K}, \mathrm{Mg}$, and Ca) clusters, the adsorption energy is obviously more negative, and the $\mathrm{N}-\mathrm{N}$ bond length increases slightly. When $\mathrm{N}_{2}$ is adsorbed on $\mathrm{M}$ atoms (including on $\mathrm{M}-\mathrm{Mo}$ ), the adsorption energy on $\mathrm{Mo}_{2} \mathrm{Li} / \mathrm{Mg} / \mathrm{Ca}$ is more negative than on $\mathrm{Mo}_{2}$, and the $\mathrm{N}-\mathrm{N}$ bond length of $\mathrm{Mo}_{2} \mathrm{Mg}$ and $\mathrm{Mo}_{2} \mathrm{Ca}$ increases obviously. It can be seen that the addition of alkali or alkaline earth metal atoms into $\mathrm{Mo}_{2}$ will increase the stability of $\mathrm{N}_{2}$ adsorption and the activation of $\mathrm{N}_{2}$.

\subsubsection{Dissociation reaction path of $\mathrm{N}_{2}$ on $\mathrm{Mo}_{2} \mathrm{M}$}

Based on the study of nitrogen adsorption, we use TPSS functional to calculate the dissociation paths of nitrogen molecules at two different initial adsorption sites (Figs. 3 and 4). Taking the energy sum of the separated $\mathrm{Mo}_{2} \mathrm{M}$ and $\mathrm{N}_{2}$ as the reference, the relative energies of the intermediates and transition states are considered.

Fig. 3 shows the reaction paths for the initial adsorption site of $\mathrm{N}_{2}$ on a single Mo atom, including the structure of the intermediates and transition states (Fig. 3a) and their relative energy with respect to the separate reactants (Fig. 3b). The reaction paths of systems with three kinds of alkali metal atoms ( $\mathrm{Li}, \mathrm{Na}$, and $\mathrm{K}$ ) are similar, so we discuss them by taking $\mathrm{Mo}_{2} \mathrm{Li}_{-} \mathrm{N}_{2}$ as an example. When $\mathrm{N}_{2}$ approaches the Mo atom of $\mathrm{Mo}_{2} \mathrm{M}$, it is adsorbed on the Mo atom in the form of end-on coordination (forming the intermediate 16). By overcoming the energy barrier of $0.16 \mathrm{eV}, \mathrm{N}_{2}$ is transferred to $\mathrm{Li}$ and $\mathrm{Mo}$ atoms, and the intermediate 17 is obtained, in which $\mathrm{N}_{2}$ is adsorbed on $\mathrm{Li}$ and Mo atoms in the form of side-on:end-on coordination. Next, a relatively high energy barrier $(0.97 \mathrm{eV})$ needs to be overcome to obtain the key intermediate I8. In I8, $\mathrm{N}_{2}$ connects with three metal atoms of Mo-Mo-Li in the coordination mode of endon:end-on:side-on. In order to dissociate the $\mathrm{N}-\mathrm{N}$ bond completely, it is necessary to overcome a very low 
energy barrier $(0.04 \mathrm{eV})$ to form a stable configuration (19). The $\mathrm{N}-\mathrm{N}$ bond dissociates completely (I10) with a high energy barrier $(0.62 \mathrm{eV})$. From the change of reaction energy (Fig. 3b) for five systems, it can be seen that the barriers for $\mathrm{N}_{2}$ transfer on $\mathrm{Mo}_{2} \mathrm{Li}, \mathrm{Mo}_{2} \mathrm{Na}$, and $\mathrm{Mo}_{2} \mathrm{~K}$ clusters are 0.97, 1.10, and $1.10 \mathrm{eV}$, respectively, at $17 \rightarrow \mathrm{TS} 6 \rightarrow \mid 8$, and $0.62,0.65$, and $0.67 \mathrm{eV}$ to dissociate the $\mathrm{N}-\mathrm{N}$ bond at $19 \rightarrow \mathrm{TS} 8 \rightarrow \mid 10$, respectively. In addition, from the point of view of thermodynamics, the reaction exotherms of the three systems are $-1.86,-1.42$, and $-1.44 \mathrm{eV}$, respectively. Therefore, no matter from the point of view of thermodynamics or kinetics, $\mathrm{Mo}_{2} \mathrm{Li} / \mathrm{Na} / \mathrm{K}$ clusters have similar reactivity towards $\mathrm{N}_{2}$, and $\mathrm{Mo}_{2} \mathrm{Li}$ is the most reactive one.

The reaction paths of clusters with two kinds of alkaline earth metal atoms ( $\mathrm{Mg}, \mathrm{Ca})$ are similar to alkali metal systems. The only difference is that in the process of dissociating the $\mathrm{N}-\mathrm{N}$ bond, the alkaline earth metal system does not need to go through the intermediate 19 , and only needs one step (18 $\rightarrow$ TS8 $\rightarrow \mid 10)$ to get the dissociated product. For $\mathrm{N}_{2}$ transfer process on the cluster $(17 \rightarrow \mathrm{TS} 6 \rightarrow 18$ ), the energy barrier (1.14 $\mathrm{eV}$ ) of $\mathrm{Mo}_{2} \mathrm{Mg}$ cluster is higher than those of the alkali metal system, while that of the $\mathrm{Mo}_{2} \mathrm{Ca}$ cluster $(0.98 \mathrm{eV})$ is lower than those of the $\mathrm{Na} / \mathrm{K}$ systems and only $0.01 \mathrm{eV}$ higher than that of the Li system. In the process of $\mathrm{N}_{2}$ dissociation ( $18 \rightarrow \mathrm{TS} 8 \rightarrow 110$ ), the energy barriers $\left(0.56\right.$ and $0.44 \mathrm{eV}$ ) that $\mathrm{Mo}_{2} \mathrm{Mg}$ and $\mathrm{Mo}_{2} \mathrm{Ca}$ clusters need to overcome is lower than that for the complete dissociation of $\mathrm{N}-\mathrm{N}$ bond in the doped alkali metal systems in step $19 \rightarrow T S 8 \rightarrow I 10(>0.6 \mathrm{eV})$. In terms of the energy relative to the reactants, the energies of the transition states of the $\mathrm{Mo}_{2} \mathrm{Ca}$ system during $\mathrm{N}_{2}$ transfer (TS6) and $\mathrm{N}-\mathrm{N}$ bond dissociation (TS8) are 0.08 and $0.01 \mathrm{eV}$, respectively, which are much lower than those of $\mathrm{Mo}_{2} \mathrm{Li}$ $(0.20$ and $0.38 \mathrm{eV})$. In addition, the exotherm of the whole reaction for $\mathrm{Mo}_{2} \mathrm{Ca}$ system reaches $2.28 \mathrm{eV}$, which is also the largest. Therefore, $\mathrm{Mo}_{2} \mathrm{Ca}$ has relatively highest reactivity towards $\mathrm{N}_{2}$ among all studied clusters. However, it can also be seen that the $\mathrm{N}_{2}$ transfer process in $\mathrm{Mo}_{2} \mathrm{Ca}$ system has a global energy barrier of $+0.08 \mathrm{eV}$, and the relative energy barrier is still quite large especially for the $\mathrm{N}_{2}$ transfer process $(0.98 \mathrm{eV})$. Therefore, the reaction processes need to be further optimized. Changing the initial adsorption site may affect $\mathrm{N}_{2}$ transfer process. In the following study, we will explore whether we can change the $\mathrm{N}_{2}$ transfer process by changing the initial adsorption site, to reduce the energy barrier of the reaction process.

Fig. 4 shows the reaction paths of $\mathrm{N}_{2}$ with $\mathrm{Mo}_{2} \mathrm{M}(\mathrm{M}=\mathrm{Li}, \mathrm{Na}, \mathrm{K}, \mathrm{Mg}$, and $\mathrm{Ca})$ when the initial adsorption site of $N_{2}$ is on the doped $M$ atoms. When $N_{2}$ is initially put near the alkali metal $M(M=L i, N a$, and $K)$, it will be end-on adsorbed on $M(111)$. Then $\mathrm{N}_{2}$ transfers to a more stable adsorption intermediate 112 by overcoming a small energy barrier (TS9). In I12, $\mathrm{N}_{2}$ is adsorbed on $\mathrm{M}$ and Mo with the end-on:side-on coordination mode. Although $\mathrm{N}_{2}$ is far away from Mo atoms in the initial setting, the structures will be optimized directly to 112 without any energy barriers for the systems doped with $\mathrm{Mg}$ and $\mathrm{Ca}$. The relative energy of I12 of Li and Ca systems is lower than that of the other three systems. Starting from I12, all systems need to pass through a high energy barrier (TS10) to obtain the pre-decomposition intermediate 113. The $\mathrm{N}_{2}$ transfer barriers of $\mathrm{Li}, \mathrm{Na}, \mathrm{K}, \mathrm{Mg}$, and Ca systems are $0.95,1.10,1.08,0.87$, and $0.85 \mathrm{eV}$, respectively. Compared with the values for the reaction paths with $\mathrm{N}_{2}$ initial adsorption on Mo, as shown 
in Fig. $3(0.97,1.10,1.10,1.14$, and $0.98 \mathrm{eV})$, the transfer energy barriers on alkali metal systems are similar in both cases, which are about $1.00 \mathrm{eV}$, while for alkaline earth metal systems, lower transfer barriers (ca. $0.9 \mathrm{eV}$ ) are obtained. Note that the 113 structure of the $\mathrm{Mo}_{2} \mathrm{Ca}$ system is the same as the 18 in Fig. 3a, in which $\mathrm{N}_{2}$ is adsorbed on the three metal atoms of Mo-Mo-Ca with the coordination mode of end-on:end-on:side-on, while in the I13 of other systems, $\mathrm{N}_{2}$ is adsorbed on Mo-Mo-M as side-on:endon:side-on. $\mathrm{N}_{2}$ dissociation products can be obtained from 113 through a $\mathrm{N}-\mathrm{N}$ dissociation barrier (TS11). The $\mathrm{N}_{2}$ dissociation barrier of the $\mathrm{Li}, \mathrm{Na}, \mathrm{K}, \mathrm{Mg}$, and $\mathrm{Ca}$ systems are $0.27,0.35,0.41,0.29$, and $0.44 \mathrm{eV}$, respectively. Compared with the values for the reaction paths with $\mathrm{N}_{2}$ initial adsorption on Mo $(0.62,0.65$, $0.67,0.56$, and $0.44 \mathrm{eV}$ ), the energy barrier decreases by about $0.3 \mathrm{eV}$ for all systems, except $\mathrm{Mo}_{2} \mathrm{Ca}$. Thus, different reaction paths and lower energy barriers are obtained by changing the initial adsorption configuration of $\mathrm{N}_{2}$. Besides, from a thermodynamic point of view, the exotherm of reaction has generally increased, from $-1.86,-1.42,-1.44,-1.42$, and $-2.28 \mathrm{eV}$ (Fig. 3) to $-2.04,-1.73,-1.77,-1.64$, and -2.28 eV (Fig. 4).

\subsection{Dissociation paths of $\mathrm{N}_{2}$ on $\mathrm{MoCa}_{2}$ and $\mathrm{Ca}_{3}$}

In the above studies on $\mathrm{Mo}_{2} \mathrm{M}$ cluster systems, $\mathrm{N}_{2}$ transfer barriers (TS10) and dissociation barriers (TS11) in each reaction path are all higher than the initial energy of the reactants, except $\mathrm{Mo}_{2} \mathrm{Ca} . \mathrm{Mo}_{2} \mathrm{Ca}$ has the highest reactivity towards $\mathrm{N}_{2}$, but the energy of the transition state for $\mathrm{N}-\mathrm{N}$ dissociation is still higher than the initial energy by $0.01 \mathrm{eV}$. Therefore, $\mathrm{N}_{2}$ dissociation may not occur in all these systems because of kinetic forbidden. Considering that the introduction of one $\mathrm{Ca}$ atom has excellent promoting effects on the reaction process, it is desired to further explore the systems with more $\mathrm{Ca}$ atoms to achieve even higher reactivity towards $\mathrm{N}_{2}$ activation. Therefore, the reactions of $\mathrm{N}_{2}$ with $\mathrm{MoCa}_{2}$ and $\mathrm{Ca}_{3}$ clusters were studied and the results are shown in Fig. 5.

After adsorption of $\mathrm{N}_{2}$, the ground state of the $\mathrm{MoCa}_{2} \mathrm{~N}_{2}$ cluster system is triplet state, while that of the $\mathrm{Ca}_{3} \mathrm{~N}_{2}$ cluster system is singlet state. The research experience of the previous system shows that different initial adsorption configurations may lead to different reaction paths and reactivities. Therefore, for $\mathrm{MoCa}_{2}$ system, we also consider two initial adsorption configurations of $\mathrm{N}_{2}$.

In the $\mathrm{MoCa}_{2}-1$ path, $\mathrm{N}_{2}$ is first adsorbed on the Mo atom in the form of end-on (115), and then after passing through two tiny energy barriers (TS12 and TS13, $<0.01 \mathrm{eV}$ ), two intermediates are obtained, in which $\mathrm{N}_{2}$ is end-on:side-on adsorbed on Mo-Ca two atoms in 116 and end-on:side-on:side-on adsorbed on Mo-Ca-Ca three atoms in 117. 117 in $\mathrm{MoCa}_{2}-1$ is very stable with the adsorption energy of $\mathrm{N}_{2}$ as $-1.75 \mathrm{eV}$, which is the largest absolute value for the adsorption energy of molecular $\mathrm{N}_{2}$ on the studied clusters in this work. For comparison, the largest value for $\mathrm{Mo}_{2} \mathrm{M}$ clusters is $-0.90 \mathrm{eV}$ of 112 in $\mathrm{Mo}_{2} \mathrm{Ca}$ reaction system. The $\mathrm{N}-\mathrm{N}$ bond in $\mathrm{I17}$ is then dissociated to produce the final product I18. This dissociation process needs to overcome a relatively high energy barrier (TS14, $0.97 \mathrm{eV})$, which is the ratedetermining step of the whole reaction. Although this barrier is still quite high, the relative energy of TS14 
is $-0.73 \mathrm{eV}$, which is well below the total energy of the reactants, indicating that this reaction can occur in gas-phase experiments. The whole $\mathrm{MoCa}_{2}-1$ reaction path is exothermic by $-1.75 \mathrm{eV}$, indicating that this reaction path is also thermodynamically feasible.

In the $\mathrm{MoCa}_{2}-2$ path, $\mathrm{N}_{2}$ is first adsorbed on two $\mathrm{Ca}$ atoms in the form of end-on:side-on (119). Then $\mathrm{N}_{2}$ is transferred to Mo-Ca (I20, side-on:end-on) through a relatively high energy barrier (TS15, $0.72 \mathrm{eV})$. This step is the rate-determining step of the whole reaction, and the relative energy is higher than that of the reactants $(+0.14 \mathrm{eV})$, so this reaction path cannot be realized in gas-phase experiments. After passing through a small energy barrier (TS16, $0.07 \mathrm{eV}$ ), I20 transfers to be side-on:side-on:end-on adsorbed on trimetallic Mo-Ca-Ca (121). By overcoming a relatively high energy barrier (TS17, $0.69 \mathrm{eV}$ ), the N-N bond dissociates and the final product $\mathrm{I} 22$ is obtained, in which the two $\mathrm{N}$ atoms are at the hollow position of three metal atoms and the bridge site of $\mathrm{Ca}-\mathrm{Mo}$, respectively. It is worth noting that the relative energy of 122 is extremely low $(-4.41 \mathrm{eV})$. The significant heat release here may provide enough energy for the subsequent reactions, thus promoting the follow-up reactions.

Finally, we studied the $\mathrm{N}_{2}$ dissociation reaction path on $\mathrm{Ca}_{3}$. With $\mathrm{Ca}_{3}, \mathrm{~N}_{2}$ first combine in a very weak physical adsorption mode to form I23, and the calculated adsorption energy is only $-0.007 \mathrm{eV}$. After that, $\mathrm{N}_{2}$ molecules adjust the adsorption mode with a negligible barrier. In I24, $\mathrm{N}_{2}$ molecules are perpendicular to the $\mathrm{Ca}_{3}$ plane and adsorbed at the center of the $\mathrm{Ca}_{3}$ triangle, but the adsorption energy is still small $(-0.16 \mathrm{eV})$. As a result, when the adsorption mode is further adjusted, the overall energy is slightly higher than the initial reactant energy $(\mathrm{TS} 24,+0.02 \mathrm{eV})$. The stable adsorption structure obtained after that has a remarkable adsorption energy $(125,-1.03 \mathrm{eV})$, and $\mathrm{N}_{2}$ is end-on:side-on:side-on adsorbed on three $\mathrm{Ca}$ atoms. The relative dissociation barrier of $\mathrm{N}-\mathrm{N}$ is quite small, only $0.32 \mathrm{eV}$ (TS20), further indicating that $\mathrm{Ca}$ atoms is beneficial for $\mathrm{N}-\mathrm{N}$ bond activation. The whole reaction path is exothermic by $-1.78 \mathrm{eV}$, just similar to the case in $\mathrm{MoCa}_{2}-1$ path.

\subsection{Analysis of intermediates and transition states in typical reaction systems}

In order to better understand the activation process of the $\mathrm{N}-\mathrm{N}$ bond on clusters, we studied the variation of four properties of the $\mathrm{N}-\mathrm{N}$ bond in the reaction process, namely, $\mathrm{N}-\mathrm{N}$ bond length $\left(R_{\mathrm{N}-\mathrm{N}}\right)$, Mayer bond order $\left(\mathrm{MBO}_{\mathrm{N}-\mathrm{N}}\right), \mathrm{N}-\mathrm{N}$ bond vibration frequency $\left(v_{\mathrm{N}-\mathrm{N}}\right)$ and Hirshfeld charge transfer onto $\mathrm{N}_{2}\left(Q_{\mathrm{N} 2}\right)$. Compared with the values of free-state $\mathrm{N}_{2}$ molecules calculated by DFT at the same theoretical level, if the $\mathrm{N}-\mathrm{N}$ bond in the system has an increased $R_{\mathrm{N}-\mathrm{N}}$, decreased $\mathrm{MBO}_{\mathrm{N}-\mathrm{N}}$ and $v_{\mathrm{N}-\mathrm{N}}$, and enlarged $Q_{\mathrm{N} 2}$, it means that the $\mathrm{N}-\mathrm{N}$ bond is activated to some extent. Therefore, these four properties are selected as index properties to measure the $\mathrm{N}_{2}$ activation degree. Four reaction paths, namely, reactions on $\mathrm{Mo}_{2}(\mathrm{Fig}$. 1), $\mathrm{Mo}_{2} \mathrm{Ca}$ (initial $\mathrm{N}_{2}$ adsorption on Ca, Fig. 4), $\mathrm{MoCa}_{2}$ (initial $\mathrm{N}_{2}$ adsorption on Mo, i.e., $\mathrm{MoCa}_{2}-1$ in Fig. 5), and $\mathrm{Ca}_{3}$ (Fig. 5) were selected. The variation of four properties are shown in Fig. 6 (data for other systems are given in the Supporting Information). 
In Fig. 6, I3 (also I13, I17, and I25) is the last intermediate just before $\mathrm{N}-\mathrm{N}$ bond dissociation. Before the position of $\mathrm{I} 3$ is the transfer process of $\mathrm{N}_{2}$ on these clusters, while after $\mathrm{I} 3$ the $\mathrm{N}_{2}$ dissociates. Generally, the $\mathrm{N}-\mathrm{N}$ on $\mathrm{Mo}_{2}$ clusters has shorter $R_{\mathrm{N}-\mathrm{N}}$, larger $\mathrm{MBO}_{\mathrm{N}-\mathrm{N}}$ and $v_{\mathrm{N}-\mathrm{N}}$, and less $Q_{\mathrm{N} 2}$ than those on the other clusters, especially for 13 and TS3. This indicates that the clusters containing $\mathrm{Ca}$ atoms have a higher ability to activate $\mathrm{N}_{2}$ bonds than $\mathrm{Mo}_{2}$ clusters. Taking $\mathrm{MoCa}_{2}$ as an example, the activation process of $\mathrm{N}_{2}$ is as follows (see also Fig. 5). When $\mathrm{N}_{2}$ is adsorbed on $\mathrm{MoCa}_{2}$ cluster in the form of end-on:side-on, the corresponding $R_{\mathrm{N}-\mathrm{N}}, \mathrm{MBO}_{\mathrm{N}-\mathrm{N}}, v_{\mathrm{N}-\mathrm{N}}$, and $Q_{\mathrm{N} 2}$ are changed from free $\mathrm{N}_{2}\left(1.10 \AA, 2.82,2373 \mathrm{~cm}^{-1}\right.$, and 0 |el) to $115\left(1.14 \AA 2.29,1971 \mathrm{~cm}^{-1}\right.$, and $\left.-0.23 \mid \mathrm{el}\right)$, indicating that activation of $\mathrm{N}_{2}$ is not very evident. After 115 is TS12, which has a similar structure to 115 and the activation of $N_{2}$ in TS12 $(1.15 \AA, 2.22,1932$ $\mathrm{cm}^{-1}$, and $\left.-0.27|\mathrm{e}|\right)$ is also similar to that in 115 . This is just corresponding to the tiny energy barrier from 115 to TS12. After TS12, 116 is obtained in which $\mathrm{N}_{2}$ is adsorbed on two metal atoms in the form of endon:side-on. The corresponding four index properties become $1.21 \AA, 1.58,1588 \mathrm{~cm}^{-1}$, and $-0.44|\mathrm{e}|$, indicating that the $\mathrm{N}-\mathrm{N}$ bond has been activated to some extent. $\mathrm{N}_{2}$ further changes the adsorption mode on $\mathrm{MoCa}_{2}$ to get 117 through TS13. TS13 is similar to I16, just as the previous case of TS12 to I15. I17 is the last intermediate before $\mathrm{N}-\mathrm{N}$ dissociation, in which $\mathrm{N}_{2}$ is end-on:side-on:side-on adsorbed on Mo-CaCa three atoms. The interaction between $\mathrm{N}_{2}$ and the cluster is strong according to the highest adsorption

energy among all studied clusters. The four index properties of 117 are $1.27 \AA, 0.91,1332 \mathrm{~cm}^{-1}$, and -0.68 $\mid \mathrm{e}$, indicating that the $\mathrm{N}-\mathrm{N}$ bond has been activated to a high enough level, and the $\mathrm{N} \equiv \mathrm{N}$ triple bond now becomes an $\mathrm{N}-\mathrm{N}$ single bond. The following $\mathrm{N}-\mathrm{N}$ dissociation becomes not too hard with a relatively low energy barrier for the transition state TS14. The activation degree of $\mathrm{N}-\mathrm{N}$ bond in TS14 is further improved to $1.91 \AA, 0.45,758 \mathrm{~cm}^{-1}$, and -0.78 lel, and finally $\mathrm{N}-\mathrm{N}$ dissociates into adsorbed two $\mathrm{N}$ atoms.

\section{Conclusions}

In this work, we explored clusters with high activity for nitrogen activation by using DFT calculations on the reactions of $\mathrm{N}_{2}$ with well-designed metal clusters. The reaction of $\mathrm{N}_{2}$ on $\mathrm{Mo}_{2}$ cluster was calculated at first, and the results show that $\mathrm{Mo}_{2}$ is inert to $\mathrm{N}_{2}$. Then, the reactions of $\mathrm{N}_{2}$ with $\mathrm{Mo}_{2} \mathrm{M}(\mathrm{M}=\mathrm{Li}, \mathrm{Na}, \mathrm{K}, \mathrm{Mg}$, and $\mathrm{Ca}$ ) were calculated. Two initial adsorption sites for $\mathrm{N}_{2}$ have been tested, which may cause different reaction paths. The results show that doping with one alkali or alkaline earth metal atom can promote the reactions by increasing the adsorption energy of $\mathrm{N}_{2}$ and reducing the energy barriers for both transfer and dissociation of $\mathrm{N}_{2}$ on clusters. Among them, $\mathrm{Mo}_{2} \mathrm{Ca}$ cluster has the highest ability to activate $\mathrm{N}_{2}$, although the dissociation barrier is still above the energy sum of the reactants. Finally, we tried to increase the number of $\mathrm{Ca}$ atoms to obtain clusters with even higher reactivity, and $\mathrm{MoCa}_{2}$ and $\mathrm{Ca}_{3}$ were tested. In one reaction path, all the intermediates and transition states $\mathrm{N}_{2}$ on $\mathrm{MoCa}_{2}$ are well below the energy sum of the reactants, indicating the dissociation of $\mathrm{N}_{2}$ on $\mathrm{MoCa}_{2}$ can take place spontaneously in gas-phase reactions. The process of $\mathrm{N}-\mathrm{N}$ bond activation on these clusters was analyzed by investigating the variation of four index properties which can reflect the activation degree of $\mathrm{N}-\mathrm{N}$ bond 
(the bond length, the vibrational frequency, Mayer bond order, and Hirshfeld charge of $\mathrm{N}_{2}$ ). On the clusters, $\mathrm{N}_{2}$ is gradually activated by changing the adsorption mode, and the adsorption mode of $\mathrm{N}_{2}$ on three metal atoms with end-on:side-on:side-on coordination is beneficial to the final dissociation of $\mathrm{N}-\mathrm{N}$ bond. This work shows a practical process to search for model systems with high activity. Trimetallic active sites with alkali or alkaline earth metal atoms are suggested to have high reactivity towards $\mathrm{N}_{2}$ activation, which may be used as a guide to design the active sites of single-cluster catalysts for nitrogen activation and conversion.

\section{Declarations}

Funding This work was financially supported by the National Natural Science Foundation of China (92161115, 61704054), the Fundamental Research Fund for the Central Universities (JB2015RCY03, JB2019MS052, JB2017MS056), and Beijing Natural Science Foundation (2214064).

Conflict of interest The authors declare no competing interests.

Author contributions Xue-Qian Huang: Writing - original draft, Investigation. Xun-Lei Ding: Supervision, Project administration, Writing - review \& editing. Jian Wang: Data curation, visualization. Ya-Ya Wang: Conceptualization, review. Joseph Israel Gurti: Data curation, review. Yan Chen: Data curation, Validation. Meng-Meng Wang: Validation, review. Wei Li: Conceptualization, Project administration. Xin Wang: Methodology, Validation.

Availability of and data and material The authors confirm that the data supporting the findings of this sstudy are available within the article and its supplementary materials.

Code availability Not applicable

\section{References}

1 Erisman J-W, Sutton M-A, Galloway J, Klimont Z, Winiwarter W (2008). Nat. Ggosci. 1:636-639.

2 Guo J, Chen P (2017). Chem 3:709-712.

3 Canfield D-E, Glazer A-N, Falkowski P-G (2010). Science 330:192-196.

4 Jia H-P, Quadrelli E-A (2014). Chem. Soc. Rev. 43:547-564.

5 Cheng Q (2008). J. Integr. Plant Biol. 50:786-798.

6 Thamdrup B (2012). Annu. Rev. Ecol. Evol. S. 43:407-428.

7 Shilov A-E (2003). Russ. Chem. Bull. 52:2555-2562.

8 Himmel H-J, Reiher M (2006). Angew. Chem. Int. Ed. 45:6264-6288. 
9 Schlçgl R (2003). Angew. Chem. Int. Ed. 42:2004-2008.

10 Schlçgl R (2008). in Handbook of Heterogeneous Catalysis (Ed.: Ertl H-K-G, Scheth F, Weitkamp J), Wiley-VCH, Weinheim, pp. 2501-2575.

11 Honkala K (2005). Science 307:555-558.

12 Logadóttir Á, Nørskov J-K (2003). J. Catal. 220:273-279.

13 Ertl G, Lee S-B, Weiss M (1982). Surf. Sci. 114:515-526.

14 Fryzuk M-D, Johnson S-A (2000). Coord. Chem. Rev. 200-202:379-409.

15 Cherkasov N, lbhadon A-O, Fitzpatrick P (2015). Chem. Eng. Process. 90:24-33.

16 Chen J-G, Crooks R-M, Seefeldt L-C, Bren K-L, Bullock R-M, Darensbourg M-Y, Holland P-L, Hoffman B, Janik M-J, Jones A-K, Kanatzidis M-G, King P, Lancaster K-M, Lymar S-V, Pfromm P, Schneider W-F, Schrock R-R (2018). Science 360:eaar6611.

17 Qiao B, Wang A, Yang X, Allard L-F, Jiang Z, Cui Y, Liu J, Li J, Zhang T (2011). Nat. Chem. 3:634-641.

18 Yang W, Zhao M, Ding X-L, Ma K, Wu C, Gates I-D, Gao Z (2020). Phys. Chem. Chem. Phys. 22:39833989.

19 Gao Z-Y, Yang W-J, Ding X-L, Lv G, Yan W-P (2018). Phys. Chem. Chem. Phys. 20:7333-7341.

20 Wang D, Ding X-L, Liao H-L, Dai J-Y (2019). Acta Phys.-Chim. Sin. 35:1005-1013.

21 Chen Z-W, Yan J-M, Jiang Q (2018). Small Methods 3:1800291.

22 Guo X, Gu J, Lin S, Zhang S, Chen Z, Huang S (2020). J. Am. Chem. Soc. 142:5709-5721.

23 Liu J-C, Ma X-L, Li Y, Wang Y-G, Xiao H, Li J (2018). Nat. Commun. 9:1610.

24 Ma X-L, Liu J-C, Xiao H, Li J (2018). J. Am. Chem. Soc. 140:46-49.

25 Lang S-M, Bernhardt T-M (2012). Phys. Chem. Chem. Phys. 14:9255-9269.

26 O’Hair R-A-J, Khairallah G-N (2004). J. Cluster Sci. 15:331-363.

27 Schwarz H (2017). Catal. Sci. Technol. 7:4302-4314.

28 Yin S, Bernstein E-R (2012). Int. J. Mass Spectrom. 321:49-65.

29 Liu J (2017). ACS Catal. 7:34-59.

30 Sugawara K-i, Yamaguchi W, Shimoi Y, Murakami J (2017). Chem. Phys. Lett. 667:267-271. 
31 Kumar D, Pal S, Krishnamurty S (2016). Phys. Chem. Chem. Phys. 18:27721-27727.

32 Kerpal C, Harding D-J, Lyon J-T, Meijer G, Fielicke A (2013). J. Phys. Chem. C 117:12153-12158.

33 Geng C, Li J, Weiske T, Schwarz H (2018). Proc. Natl. Acad. Sci. USA. 115:11680-11687.

34 Dillinger S, Mohrbach J, Niedner-Schatteburg G (2017). J. Chem. Phys. 147:184305.

35 Wang Y-Y, Ding X-L, Gurti J-I, Chen Y, Li W, Wang X, Wang W-J, Deng J-J (2021). ChemPhysChem 22:1645-1654.

36 Mou L-H, Liu Q-Y, Zhang T, Li Z-Y, He S-G (2018). J. Phys. Chem. A 122:3489-3495.

37 Li Z-Y, Mou L-H, Wei G-P, Ren Y, Zhang M-Q, Liu Q-Y, He S-G (2019). Inorg. Chem. 58:4701-4705.

38 Geng C, Li J, Weiske T, Schwarz H (2019). Proc. Natl. Acad. Sci. USA 116:21416-21420.

39 Cheng X., Li Z-Y, Mou L-H, Ren Y, Liu Q-Y, Ding X-L, He S-G (2019). Chem. Eur. J. 25:16523-16527.

40 Zhou M, Jin X, Gong Y, Li J (2007). Angew. Chem. Int. Ed. 46:2911-2914.

41 Gong Y, Zhao Y-Y, Zhou M-F (2007). J. Phys. Chem. A 111:6204-6207.

42 Mafune F, Tawaraya Y, Kudoh S (2016). J. Phys. Chem. A 120:4089-4095.

43 Jiang G-D, Mou L-H, Chen J-J, Li Z-Y, He S-G (2020). J. Phys. Chem. A 124:7749-7755.

44 Li Z-Y, Li Y, Mou L-H, Chen J-J, Liu Q-Y, He S-G, Chen H (2020). J. Am. Chem. Soc. 142:10747-10754.

45 Mou L-H, Li Y, Li Z-Y, Liu Q-Y, Ren Y, Chen H, He S-G (2020). J. Phys. Chem. Lett. 11:9990-9994.

46 Wang Y-Y, Ding X-L, Gurti J-I, Chen Y, Huang X-Q, Li W, Wang X (2021). ChemPhysChem https://doi.org/10.1002/cphc.202100771.

47 Chen Z-W, Chen L-X, Jiang M, Chen D-C, Wang Z-L, Yao X, Singh C-V, Jiang Q (2020). J. Mater. Chem. A 8:15086-15093.

48 Zhao Y, Cui J-T, Wang M, Valdivielso D-Y, Fielicke A, Hu L-R, Cheng X, Liu Q-Y, Li Z-Y, He S-G, Ma J-B (2019). J. Am. Chem. Soc. 141:12592-12600.

49 Zheng J-W, Liao F-L, Wu S, Jones G, Chen T-Y, Fellowes J, Sudmeier T, McPherson I-J, Wilkinson I, Tsang S-C-E (2019). Angew. Chem. Int. Ed. 58:17335-17341.

50 Bettens T, Pan S, Proft F-D, Frenking G, Geerlings P (2020). Chem. Eur. J. 26:12785-12793.

51 Frisch M-J, Trucks G-W, Schlegel H-B, Scuseria G-E, Robb M-A, Cheeseman J-R, Scalmani G, Barone V, Mennucci B, Petersson G-A, Nakatsuji H, Caricato M, Li X, Hratchian H-P, Izmaylov A-F, Bloino J, Zheng G, 
Sonnenberg J-L, Hada M, Ehara M, Toyota K, Fukuda R, Hasegawa J, Ishida M, Nakajima T, Honda Y, Kitao O, Nakai H, Vreven T, Montgomery J-A, Jr, Peralta J-E, Ogliaro F, Bearpark M, Heyd J-J, Brothers E, Kudin K-N, Staroverov V-N, Keith T, Kobayashi R, Normand J, Raghavachari K, Rendell A-P, Burant J-C, lyengar S-S, Tomasi J, Cossi M, Rega N, Millam J-M, Klene M, Knox J-E, Cross J-B, Bakken V, Adamo C, Jaramillo J, Gomperts R, Stratmann R-E, Yazyev O, Austin A-J, Cammi R, Promelli C, Ochterski J-W, Martin R-L, Morokuma K, Zakrzewski V-G, Voth G 26 A, Salvador P, Dannenberg J-J, Dapprich S, Daniels A-D, Farkas O, Foresman J-B, Ortiz J-V, Cioslowski J, Fox D-J (2009). Gaussian 09, Revision D.01, Gaussian, Inc., Wallingford, CT.

52 Tao J, Perdew J-P, Staroverov V-N (2003). Phys. Rev. Lett. 91:146401.

53 Chen Y, Deng J-J, Yao W-W, Gurti J-I, Li W, Wang W-J, Yao J-X, Ding X-L (2021). Phys. Chem. Chem. Phys. 23:347-355.

54 Lu T, Chen F-W (2012). J. Comput. Chem. 33:580-592.

\section{Figures}

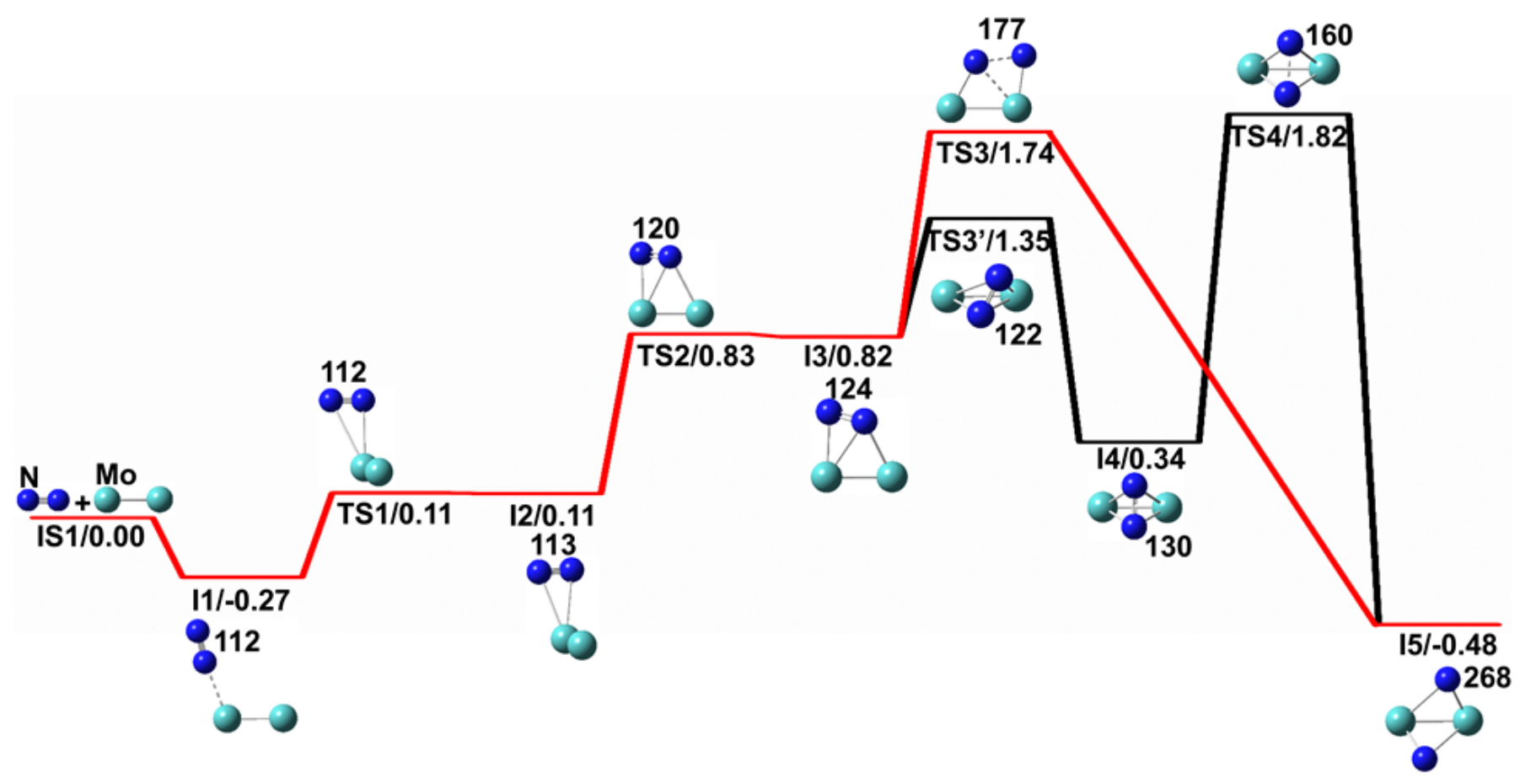

\section{Figure 1}

The reaction path of $\mathrm{Mo}_{2}$ and $\mathrm{N}_{2}$ calculated by TPSS functional. $\mathrm{N}-\mathrm{N}$ bond lengths (pm), the adsorption energy (eV) of $\mathrm{N}_{2}$ for intermediates, transition states, and products are given. 
(a)
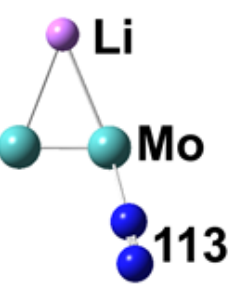

$-0.60$

(b)

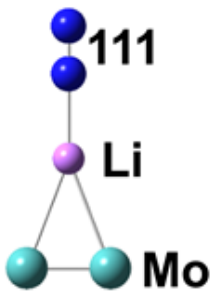

$-0.41$

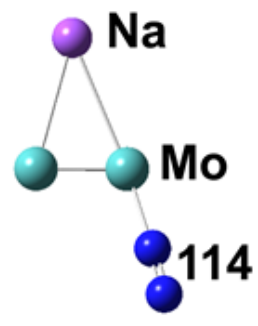

$-0.70$

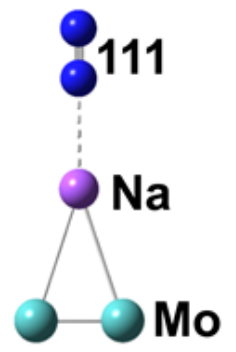

$-0.21$

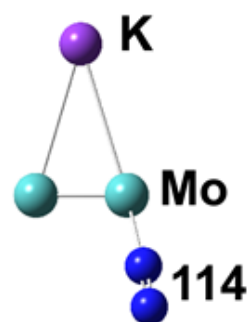

$-0.58$

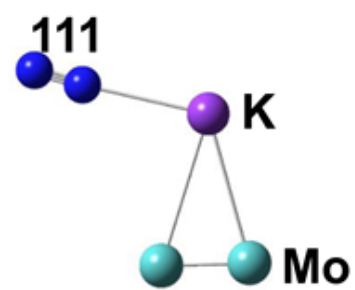

$-0.16$

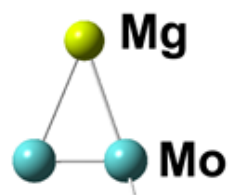

113

$-0.74$

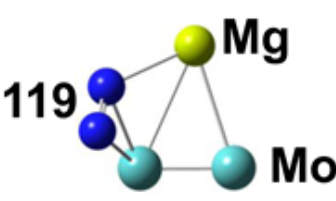

$-0.34$

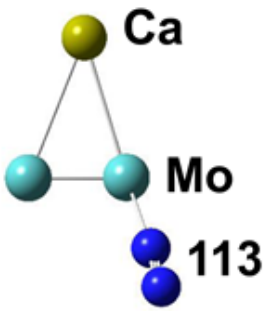

$-0.63$

Figure 2

TPSS functional calculated adsorption of $\mathrm{N}_{2}$ at different sites of trimetallic clusters $\mathrm{Mo}_{2} \mathrm{M}(\mathrm{M}=\mathrm{Li}, \mathrm{Na}, \mathrm{K}$, $\mathrm{Mg}$, and $\mathrm{Ca}$ ). One is adsorbed on the Mo atom (a), and the other is adsorbed on the $\mathrm{M}$ atom (or $\mathrm{M}-\mathrm{Mo}$ ) (b). The $\mathrm{N}-\mathrm{N}$ bond length $(\mathrm{pm})$ and the adsorption energy $(\mathrm{eV})$ of $\mathrm{N}_{2}$ are given. 
a)

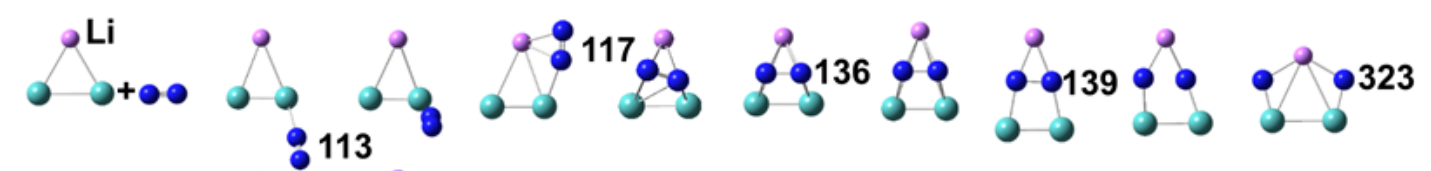

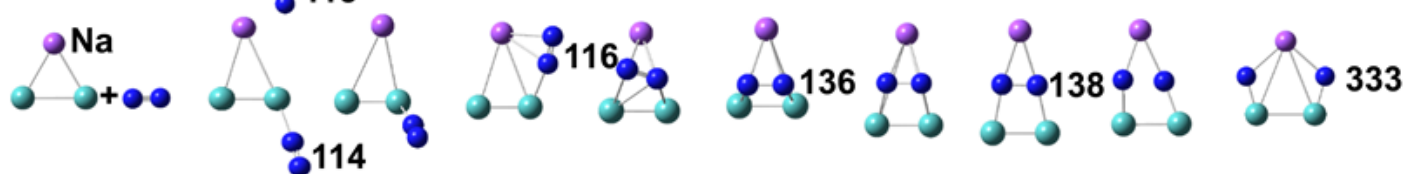

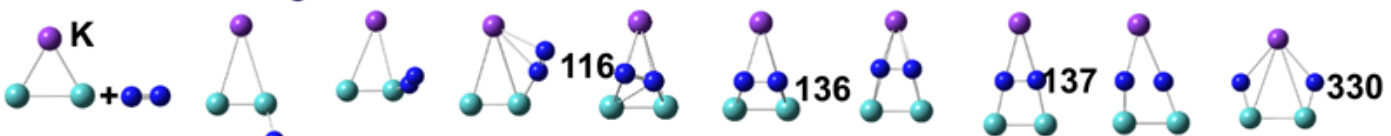

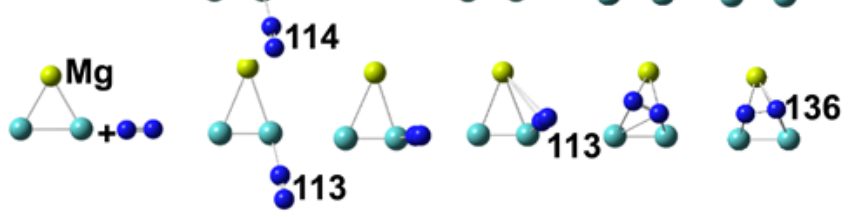

$\int_{0}^{9} 338$

b)
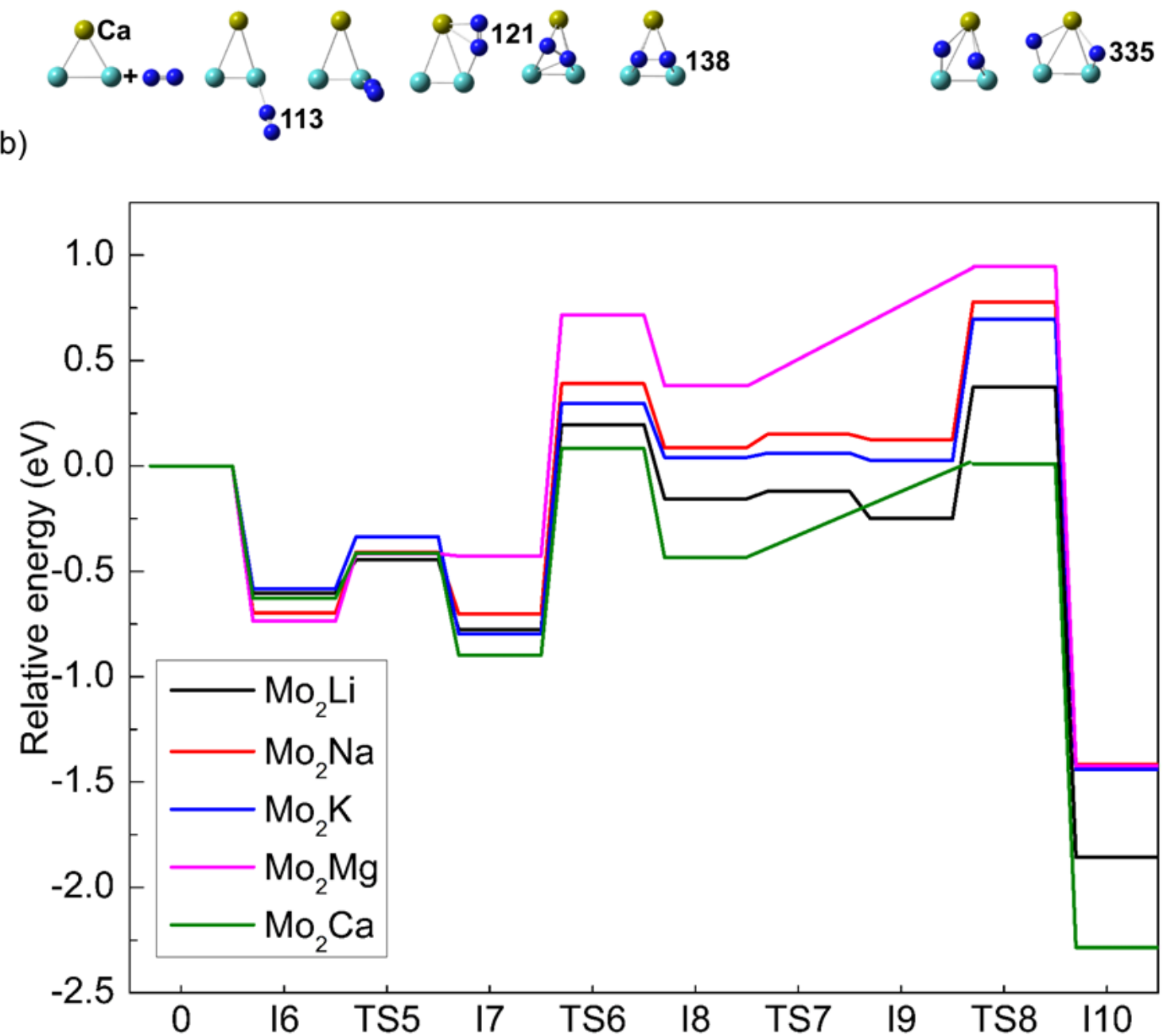

Figure 3

Reaction path of $\mathrm{Mo}_{2} \mathrm{M}\left(\mathrm{M}=\mathrm{Li}, \mathrm{Na}, \mathrm{K}, \mathrm{Mg}\right.$, and $\mathrm{Ca}$ ) with $\mathrm{N}_{2}$ when the initial adsorption site is on a single Mo atom. a) The structure of intermediates and transition states, and the $\mathrm{N}-\mathrm{N}$ bond length (pm) in intermediates. b) Relative energy with respect to the reactants. 
a) $\mathrm{Li}++\infty$

$111^{\circ}$

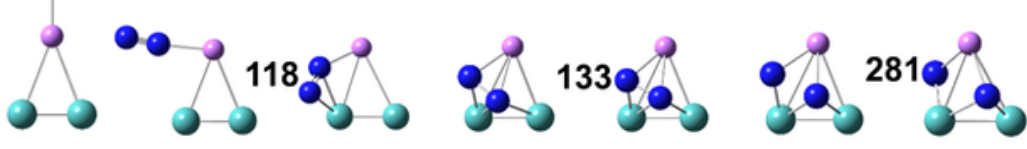

111
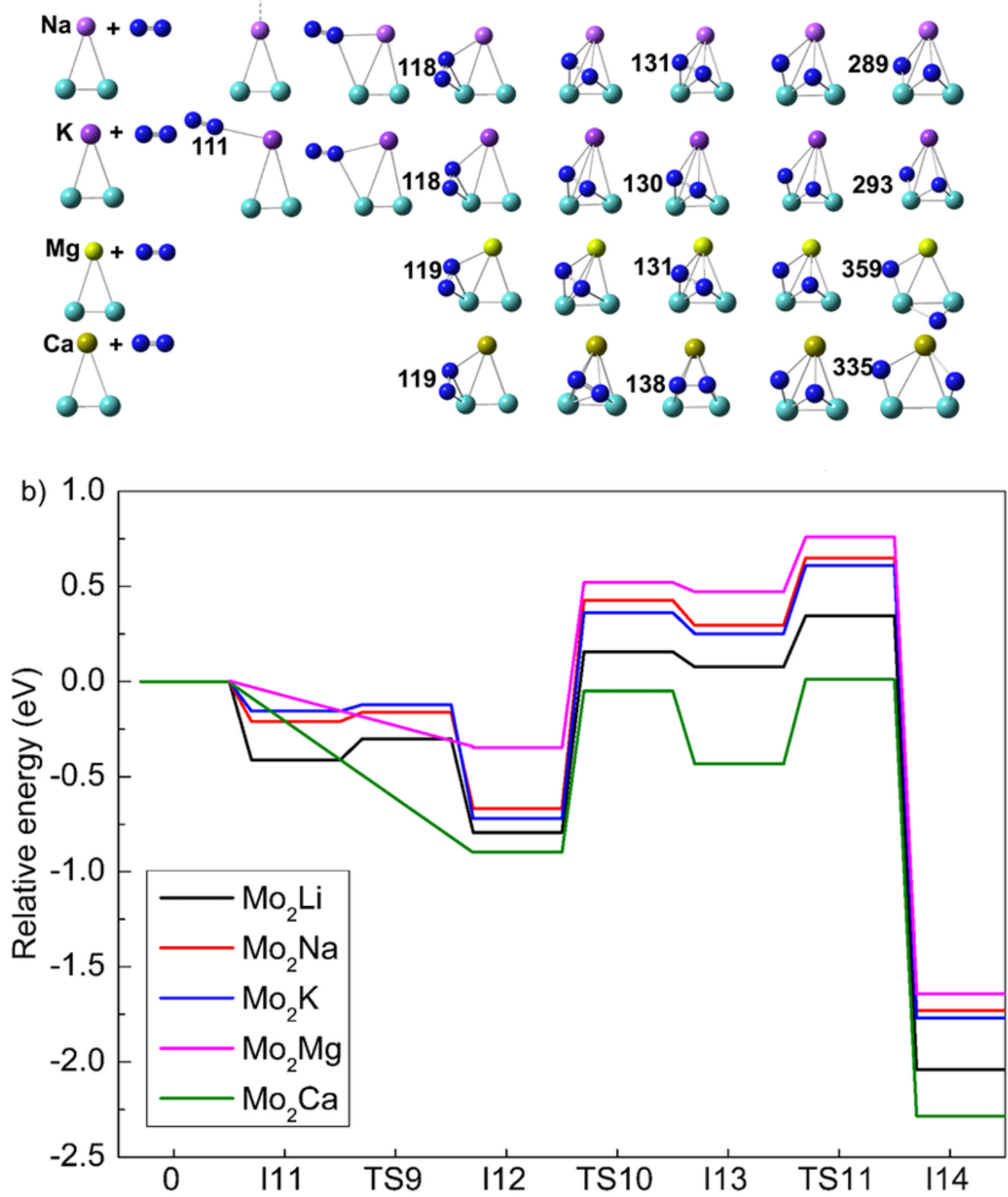

Figure 4

Reaction path of $\mathrm{Mo}_{2} \mathrm{M}\left(\mathrm{M}=\mathrm{Li}, \mathrm{Na}, \mathrm{K}, \mathrm{Mg}\right.$, and $\mathrm{Ca}$ ) with $\mathrm{N}_{2}$ when the initial adsorption site is on $\mathrm{M}$. a) The structure of intermediates and transition states, and the $\mathrm{N}-\mathrm{N}$ bond length $(\mathrm{pm})$ in intermediates. $\mathrm{b}$ ) Relative energy with respect to the reactants. 
a)
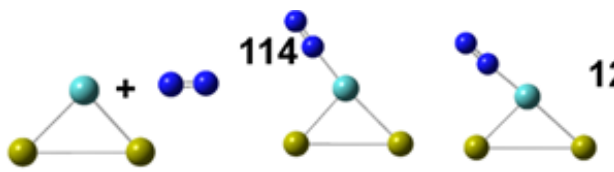

$\mathrm{MoCa}_{2}+\mathrm{N}_{2}(1) \quad I 15 \quad \mathrm{TS} 12$
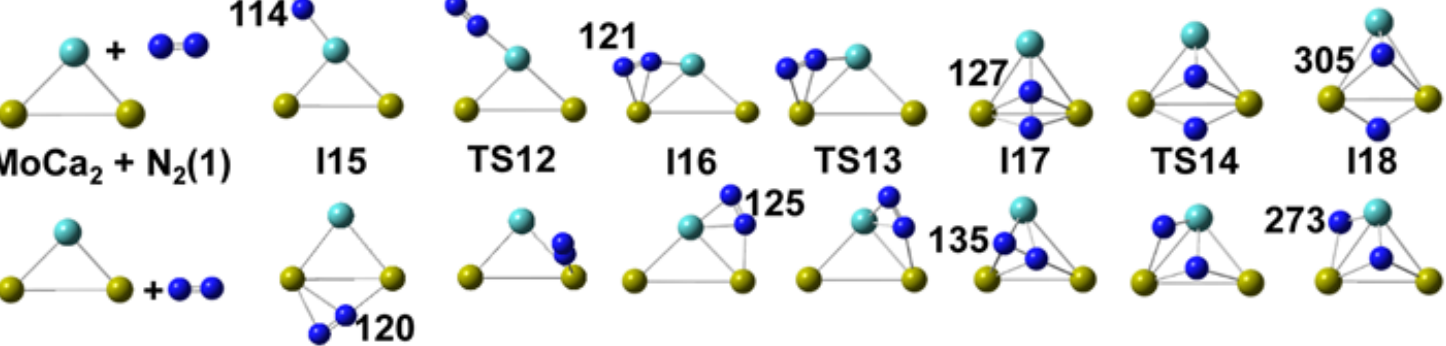

116

TS13 $\quad 117$

TS14

118
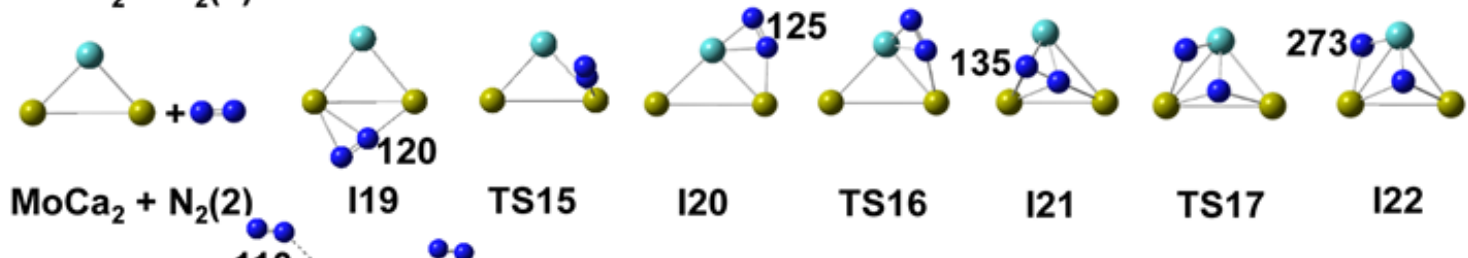

TS15

120

TS16

121

TS17

122
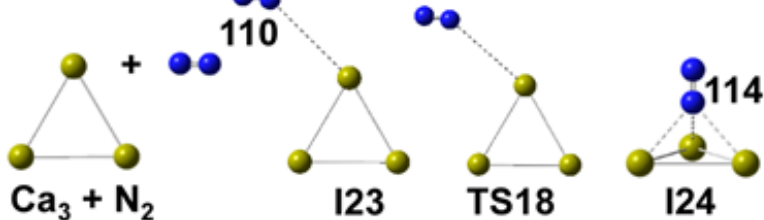

124
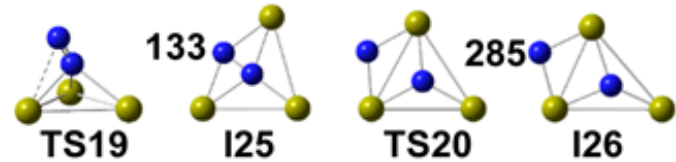

b)

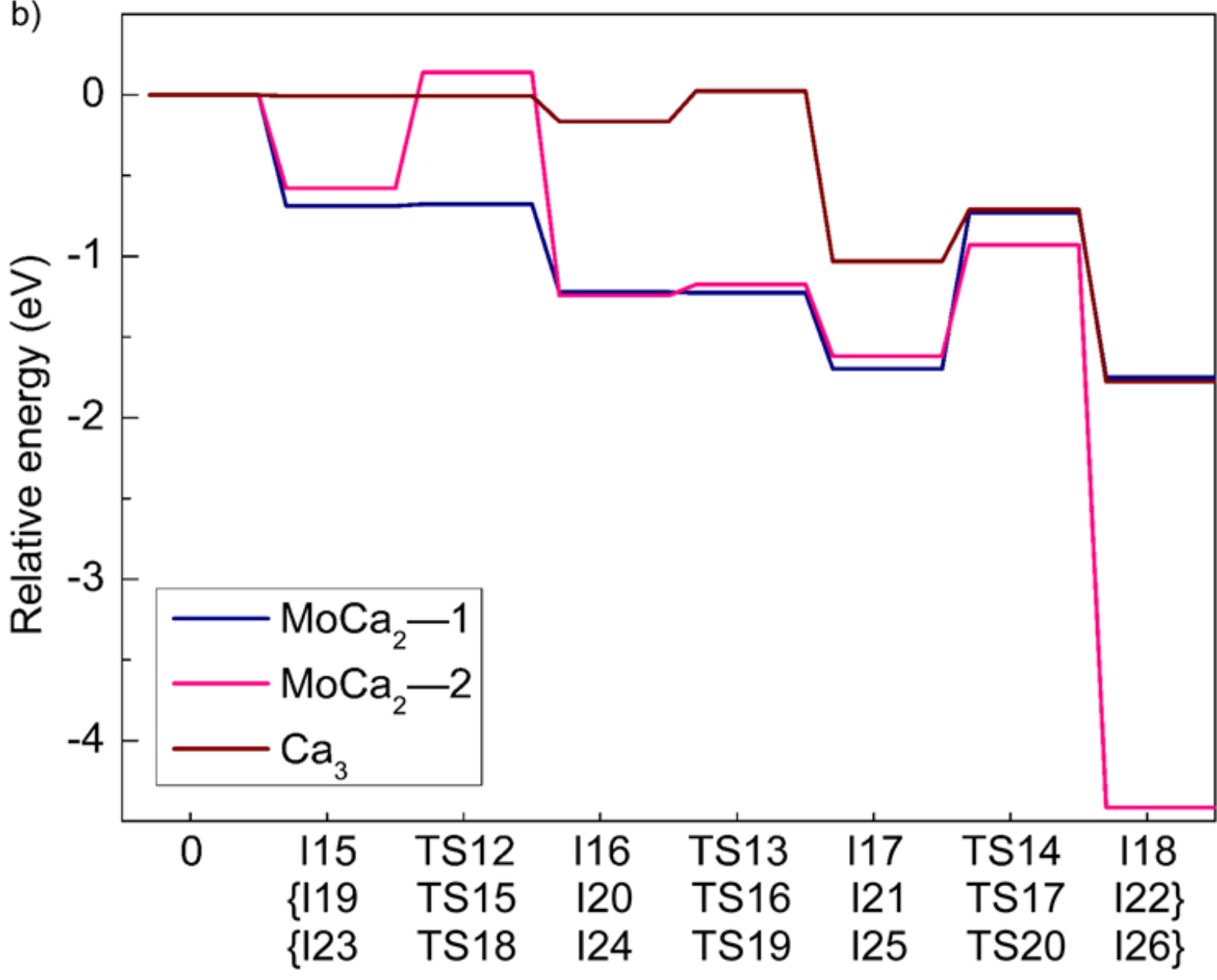

Figure 5

Reaction paths of $\mathrm{MoCa}_{2}$ and $\mathrm{Ca}_{3}$ with $\mathrm{N}_{2}$. $\mathrm{MoCa}_{2}-1$ and $\mathrm{MoCa}_{2}-2$ represent the initial adsorption of $\mathrm{N}_{2}$ on $\mathrm{Mo}$ and $\mathrm{Ca}$ atoms, respectively. a) The structure of intermediates and transition states, and the N-N bond length (pm) in intermediates. b) Relative energy with respect to the reactants. 

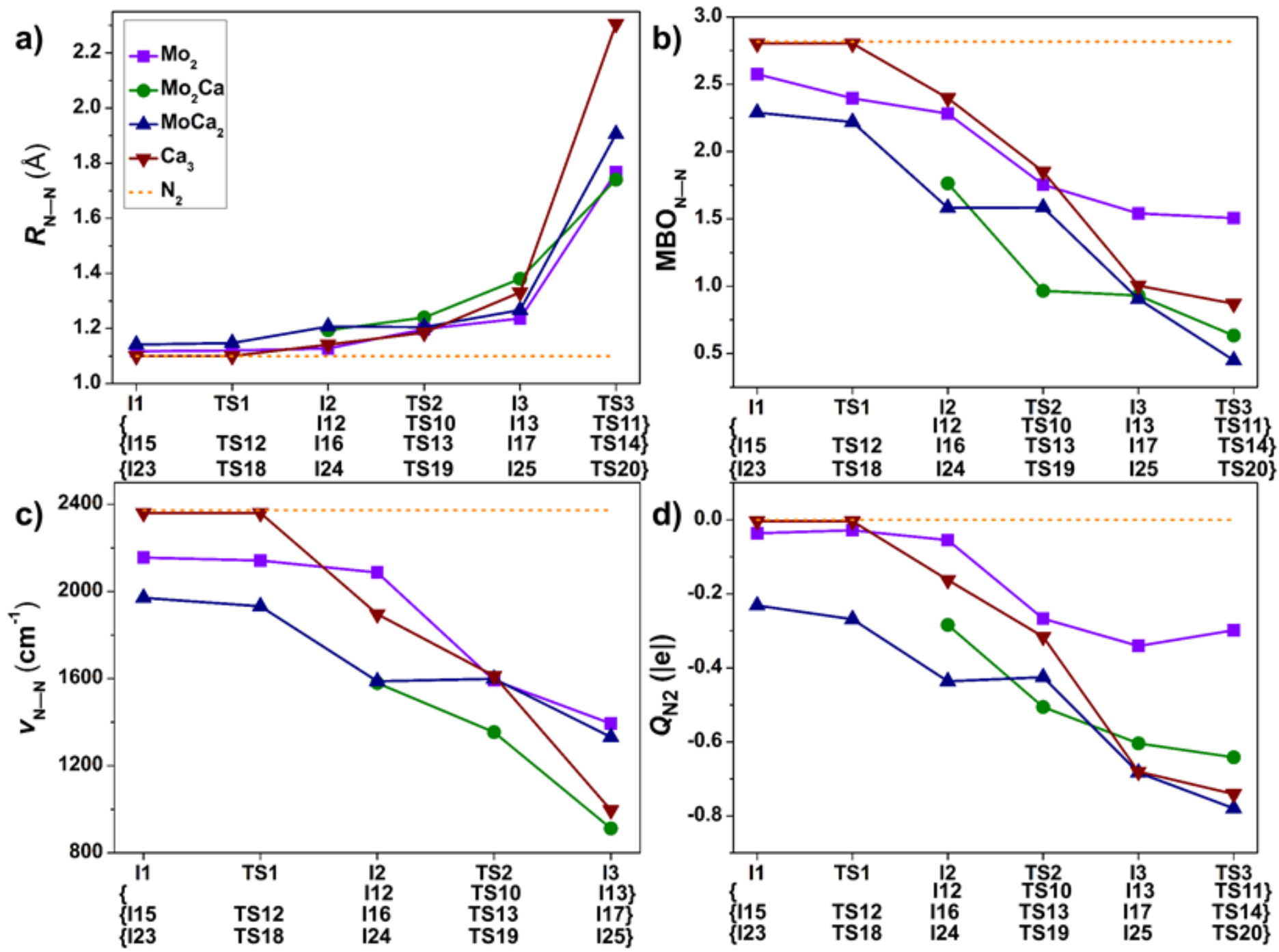

Figure 6

Four properties of the transition states and intermediates indicate the activation of $\mathrm{N}-\mathrm{N}$ bonds in the reactions of $\mathrm{Mo}_{2}, \mathrm{Mo}_{2} \mathrm{Ca}, \mathrm{MoCa}_{2}$, and $\mathrm{Ca}_{3}$ with $\mathrm{N}_{2}$. a) N-N bond lengths $\left(R_{\mathrm{N}-\mathrm{N}}\right)$, b) Mayer bond order $\left.\left(\mathrm{MBO}_{\mathrm{N}-\mathrm{N}}\right), \mathrm{c}\right) \mathrm{N}-\mathrm{N}$ bond vibration frequencies $\left(v_{\mathrm{N}-\mathrm{N}}\right)$, and d) Hirshfeld charge $\left(Q_{\mathrm{N} 2}\right)$. As a reference, the horizontal line in each figure indicates the specific property of the triple $\mathrm{N}-\mathrm{N}$ bond in free $\mathrm{N}_{2}$.

\section{Supplementary Files}

This is a list of supplementary files associated with this preprint. Click to download.

- Sl1.17.pdf 